Original Article

\title{
HEARING LOSS IN RHEUMATOID ARHRITIS
}

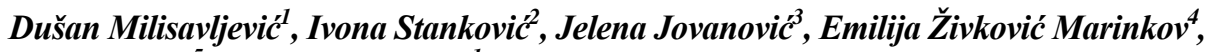 \\ Marija Krstic ${ }^{5}$, Tamara Stankovic ${ }^{1}$ \\ ${ }^{1}$ University of Niš, Faculty of Medicine, Niš, Serbia \\ ${ }^{2}$ University Clinical Center Niš, Clinic for Physical Therapy and Rehabilitation, Niš, Serbia \\ ${ }^{3}$ Institute for Cardiovascular and Rheumatologic Diseases, Niška Banja, Serbia \\ ${ }^{4}$ University Clinical Center Niš, Clinic for Otorhinolaryngology, Niš, Serbia \\ ${ }^{5}$ Public Health Institution, Niš, Serbia
}

\begin{abstract}
The incidence of hearing loss in patients with rheumatoid arthritis (RA) and the treatment have been differently reported. The aims of this study were to establish the presence and to differentiate the type of hearing loss in patients with $R A$, and to investigate the results of corticosteroid and methotrexate treatment on hearing loss in RA. Longitudinal, prospective study included 87 patients aged between 18 and 70 years diagnosed with RA. Disease Activity Score (DAS $28 \mathrm{Se}$ ) and Health Assessment Questionnaire (HAQ) were measured. 38 Patients were treated with prednisone; intratympanic appliction was used in 11 persons, and in case of weak or absent improvement after steroids methotrexate was applied for further treatment. Predominantly sensorineural hearing loss was present in $56.3 \%$ of the patients, without correlation with the duration of disease and clinical activity of RA. Corticosteroid therapy, both peroral or intratympanic contributed to hearing improvement in 60.0\%. Audiometric tests are recommended in patients who suffer from RA in order to control hearing in rheumatoid arthritis and analyze the effect of proposed therapeutic procedures.
\end{abstract}

Key words: Rheumatoid arthritis, hearing loss, corticosteroids, methotrexate, intratympanic application.

\section{Introduction}

Rheumatoid arthritis (RA) is a disease of unknown origin, characterized by disseminated erosions of articulations, and different systemic inflammatory changes. Humoral immune alterations (rheumatoid factor, interferon gamma, interleukin 2), as well as cellular alterations (lymphocyte activation) are characteristic for RA. Reduced complement, leukocytosis, increased sedimentation, and higher gammaglobuline level are usually found. The diagnosis is predominantly based on clinical, radiological, and laboratory parameters $[1,2]$.

RA causes proliferative synovitis in symmetric peripheral joints, which differentiates it from other systemic diseases of connective tissue. Frequent multiorganic changes, such as pericardial effusion, subcutaneous nodes, polyneuropathy, vasculitis, nephropathy, and keratoconjunctivitis are characteristic for RA.

Hearing and balance impairment has been documented in patients with RA. Concerning hearing loss, bilateral, symmetric, slowly progressive hypoacousia predominates in these patients $[3,4]$.

*Correspondence to: Prof. Dušan Milisavljević, $\mathrm{MD}, \mathrm{PhD}$

Faculty of Medicine, University of Niš,

81 Dr. Zoran Đinđić Blvd, 18000 Niš, Serbia

Phone: +381 184226644

E-mail: dusanorldusan@gmail.com

Received October $5^{\text {th }}, 2016$, accepted for publication January $18^{\text {th }}, 2017$
Previous researches resulted in controversial data on the incidence and treatment of hearing loss in RA [5-7].

The aims of this study were:

1. To document the presence and type of hearing loss in patients with RA.

2. To compare activity and clinical parameters of RA with hearing status.

3. To examine the effectiveness of corticosteroid and methotrexate treatment on hearing loss in RA.

\section{Patients and Methods}

Longitudinal, prospective study comprising of 87 patients aged between 18 and 70 years diagnosed with RA was conducted during the period 2002-2010 at the Institute for Rheumatology and Clinic for Otorhinolaryngology. The mean age was 56.2 \pm .8 .7 years, female to male ratio was 70:17, and average duration of disease was $13.4 \pm 6.1$ years.

The diagnosis was made according to the American College of Rheumatology Classification Criteria [1] which included: morning rigidity of joints, arthritis of more than 3 joints, arthritis of hands, all of them lasting for at least 6 weeks, subcutaneous nodes, seropositivity for RF, and radiologic erosions and decalcifications. Exclusion criteria were: other causes for conductive and sensorineural hearing loss, other systemic and chronic diseases, professional noise exposure, malignant diseases, 
use of ototoxic and immunomodulator drugs. Laboratory tests included: sedimentation rate, leukocytes, fibrinogen, immunoglobulins, CRP, and RF.

Disease Activity Score (DAS $28 \mathrm{Se}$ ) was measured and Health Assessment Questionnaire (HAQ) was conducted. DAS 28 Se is index with strong correlation to the functional ability of patients, as well as with the outcome of the disease. The results were divided into: 3.2-5.1 moderate activity, and >5.1 indicating high activity. HAQ scale comprises of 20 questions in 8 categories. The results range from 0.0 (the best) to 3.0 (the worst functional ability).

The patients gave written consent, and the study was approved by the Institutional Ethics Committee.

Control group included 40 healthy subjects with similar age (average 55.3 \pm 6.2 years), and sex ratio (F: M ratio 31:9).

Hearing threshold for seven frequencies was measured using audiometer Madsen ZO 2020. Improvement of hearing was defined as the increase for more than $15 \mathrm{~dB}$ for one frequency $(250,500,1000,2000,4000,6000,8000$ $\mathrm{Hz}$ ), or any improvement for two or more frequencies.

No previous steroid treatment was given to any patient for at least for six months.

The patients with hearing loss were offered peroral or transtympanic steroid therapy. 38 patients were treated with prednisone (30 days, peroral dose $60 \mathrm{mg} /$ day). Intratympanic appliction was used in 11 persons (methylprednisolone, weekkly $0,5 \mathrm{ml}$ in $40 \mathrm{mg} / \mathrm{ml}$ ). Weak or absent improvement after steroids was further treated by methotrexate $(7,5 \mathrm{mg} / \mathrm{wk}$, with gradual increase to $25 \mathrm{mg} / \mathrm{ml}$, for 8 weeks).

Student's t test and $\mathrm{chi}^{2}$ test were used, and statistical significance limit was defined as $\mathrm{p}<0.05$.

\section{Results}

Among patients with RA a total of 49 patients $(56.3 \%)$ had hearing loss. There were 41 females, and 8 male patients, without significant difference from the patients with normal hearing. Hearing loss was predominantly sensorineural, documented in $91.8 \%$ of them, and in other $8.2 \%$ it was conductive, or mixed. Hearing loss accompanied by tinnitus, fullness, or vertigo was verified in $19.5 \%$ of patients, while bilateral progressive sensorineural hearing loss was present in $10.3 \%$ of them. Subjective average duration of hearing loss was $3.5 \pm 2.3$ years.

Control group had hearing loss in $12.5 \%$, and it was mainly mild sensorineural. Distribution of patients across age was similar in both groups.

Longer duration of RA, as well as higher values of DAS $28 \mathrm{Se}$, and HAQ scale produced more frequent incidence of altered hearing. However, the data did not reach statistical significance for any of these parameters (Table 1).

After peroral steroid therapy hearing improvement was documented in $60.5 \%$ of the patients, while in others hearing remained the same. Intratympanic application of steroids resulted in better hearing in $63.6 \%$ of the patients (Table 2). Improvement of hearing was achieved only for higher frequencies, over $2000 \mathrm{~Hz}$. Also, better results were achieved for mild to moderate initial hearing loss, than for pronounced sensorineural alteration of hearing. After follow-up for three to five months there were no significant changes of obtained improvement (Table 3 ).

In total, $38.8 \%$ of the patients did not have any change of hearing after steroid therapy. However, only $47.4 \%$ of them accepted further methotrexate therapy. The results of such treatment were not satisfactory, with improvement in only $11.1 \%$ (Table 2).

Table 1 Clinical characteristics and hearing loss in patients with rheumatoid arthritis

\begin{tabular}{llrrrrrr}
\hline Parameter & & \multicolumn{2}{c}{ RA without HL } & \multicolumn{2}{c}{ RA with HL } & \multicolumn{2}{c}{ RA Total } \\
\multirow{2}{*}{ Sex } & Female & 29 & $(76.3 \%)$ & 41 & $(85.4 \%)$ & 70 & $(80.5 \%)$ \\
& Male & 9 & $(23.7 \%)$ & 8 & $(14.6 \%)$ & 17 & $(19.5 \%)$ \\
\hline \multirow{3}{*}{ Age (y) } & $41-50$ & 7 & $(18.4 \%)$ & 8 & $(6.3 \%)$ & 15 & $(17.2 \%)$ \\
& $51-60$ & 18 & $(47.4 \%)$ & 21 & $(42.9 \%)$ & 41 & $(47.1 \%)$ \\
& $61-70$ & 10 & $(26.3 \%)$ & 13 & $(32.6 \%)$ & 24 & $(27.6 \%)$ \\
\multirow{2}{*}{ Disease } & $>70$ & 3 & $(7.9 \%)$ & 4 & $(8.2 \%)$ & 7 & $(8.1 \%)$ \\
duration & $0-10$ & 23 & $(60.5 \%)$ & 17 & $(34.7 \%)$ & 40 & $(46.0 \%)$ \\
(y) & $11-20$ & 11 & $(30.0 \%)$ & 25 & $(51.0 \%)$ & 36 & $(41.4 \%)$ \\
& $21-30$ & 3 & $(7.9 \%)$ & 6 & $(12.3 \%)$ & 9 & $(10.3 \%)$ \\
\multirow{2}{*}{ DAS 28 Se } & $>30$ & 1 & $(2.6 \%)$ & 1 & $(2.0 \%)$ & 2 & $(2.3 \%)$ \\
& $>5.1$ & 7 & $(18.4 \%)$ & 3 & $(6.1 \%)$ & 10 & $(11.5 \%)$ \\
\multirow{2}{*}{ HAQ } & $>5.1$ & 31 & $(81.6 \%)$ & 46 & $(93.9 \%)$ & 77 & $(88.5 \%)$ \\
& $<1.0$ & 2 & $(5.3 \%)$ & 1 & $(2.0 \%)$ & 3 & $(3.4 \%)$ \\
& $1,125-2,0$ & 20 & $(52.6 \%)$ & 22 & $(44.9 \%)$ & 42 & $(48.3 \%)$ \\
& $>2.125$ & 16 & $(42.1 \%)$ & 26 & $(53.1 \%)$ & 42 & $(48.3 \%)$ \\
\hline
\end{tabular}

$\mathrm{RA}=$ rheumatoid arthritis, $\mathrm{HL}=$ hearing loss, DAS 28Se $=$ Disease Activity Score, HAQ = Health Assessment Questionnaire 
Table 2 Results of different treatment for hearing loss in rheumatoid arthritis judged by audiometry and subjective assessment of patients

\begin{tabular}{|c|c|c|c|c|c|c|c|c|c|c|}
\hline \multirow[t]{3}{*}{ Treatment } & \multirow[b]{2}{*}{ Initial HL } & \multirow[t]{2}{*}{ No } & \multicolumn{4}{|c|}{ Audiometry } & \multicolumn{4}{|c|}{ Subjective assessment } \\
\hline & & & \multicolumn{2}{|c|}{ Improved } & \multicolumn{2}{|c|}{ Unchanged } & \multicolumn{2}{|c|}{ Improved } & \multicolumn{2}{|c|}{ Unchanged } \\
\hline & $20-30 \mathrm{~dB}$ & 17 & 13 & $(76.5 \%)$ & 4 & $(23.5 \%)$ & 10 & $(58.8 \%)$ & 7 & $(41.2 \%)$ \\
\hline \multirow{3}{*}{$\begin{array}{l}\text { Cortico } \\
\text { per os }\end{array}$} & $31-40 \mathrm{~dB}$ & 16 & 9 & $(56.3 \%)$ & 7 & $(43.7 \%)$ & 6 & $(37.5 \%)$ & 10 & $(62.5 \%)$ \\
\hline & $>40 \mathrm{~dB}$ & 5 & 1 & $(20.0 \%)$ & 4 & $(80.0 \%)$ & 0 & $(0.0 \%)$ & 5 & $(100 \%)$ \\
\hline & All cases & 38 & 23 & $(60.5 \%)$ & 14 & $(36.8 \%)$ & 16 & $(42.1 \%)$ & 22 & $(57.9 \%)$ \\
\hline \multirow{4}{*}{$\begin{array}{l}\text { Cortico } \\
\text { intratymp }\end{array}$} & $20-30 \mathrm{~dB}$ & 1 & 1 & $(100 \%)$ & 0 & $(0.0 \%)$ & 1 & $(100 \%)$ & 0 & $(0.0 \%)$ \\
\hline & $31-40 \mathrm{~dB}$ & 5 & 4 & $(80.0 \%)$ & 1 & $(20.0 \%)$ & 3 & $(60.0 \%)$ & 2 & $(40.0 \%)$ \\
\hline & $>40 \mathrm{~dB}$ & 5 & 2 & $(40.0 \%)$ & 3 & $(60.0 \%)$ & 1 & $(20.0 \%)$ & 4 & $(80.0 \%)$ \\
\hline & All cases & 11 & 7 & $(63.6 \%)$ & 4 & $(36.4 \%)$ & 5 & $(45.5 \%)$ & 6 & $(54.5 \%)$ \\
\hline \multirow{4}{*}{ MTX } & $20-30 \mathrm{~dB}$ & 2 & 0 & $(0.0 \%)$ & 2 & $(100 \%)$ & 0 & $(0.0 \%)$ & 2 & $(100 \%)$ \\
\hline & $31-40 \mathrm{~dB}$ & 4 & 1 & $(25.0 \%)$ & 3 & $(75.0 \%)$ & 0 & $(0.0 \%)$ & 4 & $(100 \%)$ \\
\hline & $>40 \mathrm{~dB}$ & 3 & 0 & $(0.0 \%)$ & 3 & $(100 \%)$ & 0 & $(0.0 \%)$ & 3 & $(100 \%)$ \\
\hline & All cases & 9 & 1 & $(11.1 \%)$ & 8 & $(88.9 \%)$ & 0 & $(0.0 \%)$ & 9 & $(100 \%)$ \\
\hline
\end{tabular}

MTX = methotrexate, $\mathrm{HL}=$ hearing loss

Table 3 Improvement of hearing in $\mathrm{dB}$ after different treatment modalities and after follow-up for hearing loss in rheumatoid arthritis across frequencies.

\begin{tabular}{llcccccccc}
\hline Treatment & & $125 \mathrm{~Hz}$ & $250 \mathrm{~Hz}$ & $500 \mathrm{~Hz}$ & $1 \mathrm{KHz}$ & $2 \mathrm{~Hz}$ & $4 \mathrm{KHz}$ & $6 \mathrm{KHz}$ & $8 \mathrm{KHz}$ \\
\hline & Before & $21.4 \pm 3.2$ & $21.4 \pm 3.3$ & $21.4 \pm 3.2$ & $30.6 \pm 5.1$ & $36.5 \pm 7.1$ & $42.5 \pm 4.7$ & $48.6 \pm 7.1$ & $51.3 \pm 8.5$ \\
Cortico & After & $19.4 \pm 4.2$ & $21.4 \pm 5.1$ & $21.4 \pm 5.1$ & $26.4 \pm 3.2$ & $30.6 \pm 5.1$ & $30.6 \pm 5.1$ & $40.3 \pm 4.4$ & $42.5 \pm 4.7$ \\
per os & $\Delta \mathrm{dB}$ & 2.0 & 0.0 & 0.0 & 4.2 & $5.9^{*}$ & $11.9^{*}$ & $8.3^{*}$ & $8.8^{*}$ \\
& Follow & $19.9 \pm 5.1$ & $22.2 \pm 4.8$ & $20.7 \pm 6.1$ & $28.3 \pm 4.1$ & $32.7 \pm 6.1$ & $32.5 \pm 4.8$ & $43.2 \pm 5.6$ & $46.2 \pm 5.5$ \\
& $\Delta$ dB & 1.5 & -1.0 & 0.7 & 1.3 & 3.2 & $10.0^{*}$ & $5.4^{*}$ & $5.1^{*}$ \\
\hline \multirow{4}{*}{ Cortico } & Before & $23.8 \pm 3.4$ & $23.8 \pm 3.4$ & $23.8 \pm 3.4$ & $40.6 \pm 5.9$ & $40.6 \pm 5.9$ & $50.1 \pm 6.6$ & $54.2 \pm 7.9$ & $55.8 \pm 9.9$ \\
intratymp & After & $20.5 \pm 4.9$ & $20.5 \pm 4.9$ & $23.8 \pm 3.4$ & $36.5 \pm 7.1$ & $36.5 \pm 7.1$ & $38.7 \pm 8.2$ & $38.7 \pm 8.2$ & $44.6 \pm 9.7$ \\
& Follow & $21.7 \pm 6.3$ & $24.2 \pm 6.1$ & $22.4 \pm 5.1$ & $37.2 \pm 8.1$ & $39.7 \pm 6.2$ & $40.2 \pm 9.9$ & $35.7 \pm 7.6$ & $46.9 \pm 9.3$ \\
& $\Delta$ dB & 2.1 & -0.6 & -0.6 & 3.4 & 0.9 & $9.9^{*}$ & $18.5^{*}$ & $8.9^{*}$ \\
\hline \multirow{4}{*}{ MTX } & Before & $28.8 \pm 5.5$ & $25.6 \pm 5.9$ & $25.6 \pm 5.9$ & $30.3 \pm 9.7$ & $39.5 \pm 7.2$ & $55.1 \pm 8.5$ & $55.1 \pm 8.5$ & $54.8 \pm 7.2$ \\
& After & $28.2 \pm 3.4$ & $28.8 \pm 3.4$ & $25.6 \pm 5.1$ & $25.6 \pm 5.1$ & $35.6 \pm 7.3$ & $45.7 \pm 9.8$ & $51.1 \pm 8.0$ & $54.8 \pm 9.2$ \\
& $\Delta$ dB & -0.6 & -3.2 & 0.0 & 4.7 & 4.1 & $9.4^{*}$ & 4.0 & 0.0 \\
& Follow & $28.8 \pm 5.5$ & $26.3 \pm 7.1$ & $25.6 \pm 5.9$ & $30.7 \pm 8.3$ & $40.2 \pm 8.6$ & $45.7 \pm 9.9$ & $52.6 \pm 9.1$ & $55.3 \pm 8.7$ \\
& $\Delta$ dB & 0.0. & -0.7 & 0.0 & -0.4 & -0.7 & 5.4 & 2.5 & -0.5 \\
\hline
\end{tabular}

MTX $=$ methotrexate, ${ }^{*}=$ significant

Subjective assessment of patients concerning their hearing was comparable to audiometric data, but overall estimation of treatment improvement was lower than found on tonal audiometry (42.9\% for subjective versus $61.2 \%$ improvement for audiometry) (Table 2).

\section{Discussion}

Hearing loss in patients with rheumatoid arthritis (RA) is differently reported, usually affecting two thirds of them, but the values are ranging from $25.2 \%$ to $72.2 \%$. Hearing loss in RA was significantly worse for 200, 500 , and $6000 \mathrm{~Hz}[2,3,8]$. There are also reports that found no significant hearing loss in RA compared to control group with matched age and gender [9].

Sensorineural hearing loss in RA is attributed to vasculitis caused by immune complexes inside inner ear, antibodies against inner ear, and ototoxic effects of drugs used for treatment of RA [10].

Transient evoked otoacoustic emissions in RA were found to be lower than in controls. Distortion product of otoacoustic emissions in RA patients were similar to control $[9,11]$. Acoustic reflexes were with normal thresholds, but with occasional prolonged latency. Besides increased hearing threshold, patients with RA have higher air-bone gaps, and increased wave I latency on ABRs $[12,13]$.

Conductive hearing loss was less frequently reported in patients with RA, ranging from $4 \%$ to $17.1 \%[1,3]$. The supposed mechanisms were hypermobility of conductive middle ear mechanism, or discontinuity of ossicular chain. Tympanometric studies did not find any important changes $[1,14]$.

The incudo-malleolar and incudo-stapedial joints are true diarthroses, and may be subjected to the same 
rheumatoid lesions. Scanning electron microscopic study of auditory ossicles from patients with RA confirmed significantly higher incidence of surface and articular changes. Longer duration of disease caused more intense ossicular alterations [15].

Hearing was worse in older patients, with longer duration of disease, with active disease, and RA nodules. Decrease of hearing threshold significantly correlated to the duration of RA, with all frequencies affected after 15 years of disease [10]. The results were opposite in other studies [16]. For example, no correlation between hearing loss and age, sex, disease duration, disease characteristics, and therapy were documented [7,9,28].

There is no clear association between the activity of RA and hearing loss [1]. The increase of sedimentation rate, interleukin 6, metalloproteinase 3 correlated well, contrary to RF [3].

The recovery of hearing loss in persons with RA was not sufficiently studied. A positive result of Western Blot predicted functional recovery of hearing in patients with RA [3].

Steroid treatment of autoimmune ear diseases produced significantly better results in cases without systemic diseases (excellent results $33 \%$ versus $25 \%$ ) [17,18]. Glucocorticoids can reverse hearing loss; however, their important side effects prevent long term treatment in chronic diseases. Experimental studies in C3. MRL-Fas(lpr) autoimmune mice treated with corticoids confirmed better hearing threshold, and reduced anti-nuclear antibodies and immune complexes 19].

Methotrexate is considered as a gold standard for patients with RA, mainly because of its tolerability, efficacy, and ease of use. Methotrexate treatment was used for immune mediated cochleovestibular diseases (mean duration 12.9 months) and it improved hearing in $69.6 \%[20,21]$. Other studies concluded that methotrexate in low doses (7.5 to $20 \mathrm{mg} / \mathrm{wk}$ ) improved hearing and balance in autoimmune inner ear disease (AIED). However, later randomized, double-blind, placebo controlled trial reported that methotrexate was not effective in maintaining the hearing improvement achieved with pronisone therapy in patients with AIED [7].

Some other therapeutical modalities for hearing loss in RA were proposed and tested. TNFalpha inhibitor in combination with methotrexate was used in autoimmune sensorineural hearing loss [22]. Etanercept is a powerful antagonist of TNF that binds to and inactivates the cytokines. However, substantial efficacy of etanercept has not been confirmed for improvement of hearing in patients with immune mediated cochlovestibular disorders [23]. Vasodilatators and antioxidants were also proposed for treatment of hearing loss in RA [13]. Successful use of adalimumab was verified for RA with sensorineural hearing loss [24].

The highest levels of steroids in perilymph were found after intratympanic injection. Also, limited permeability of the blood-labyrinth barrier prevents systemic absorption of applied corticosteroids [25,26].

There were no significant differences concerning age and sex in RA patients with and without hearing loss. Also, age-matched control group eliminated the effect of possible associated presbyacousis. More importantly, duration of disease, DAS and HAQ scales indicated higher incidence of hearing affection, but the differences were not significant. So, we need more specific tests to predict inner ear changes in patients with RA [27-30].

According to the results of this study steroids resulted in hearing improvement in approximately $60.0 \%$, both for peroral and intratympanic application. Contrary to this, methotrexate had virtually no influence of hearing. The disadvantage of steroid treatment is limited time of use. Also, the prediction of success or failure of treatment is difficult. Thus, initial peroral steroid therapy is advisable in RA with hearing loss. This is also acceptable for the patients. The positive outcome of such option can be further treated with steroids intrtympanically. Though intratympanic use of steroids was reported in references, there are no references for application for hearing loss in RA [25,26].

The slight discordance found in this study between patient's assessment and audiometric findings after the therapy is very important, since the patients must use medication and tolerate its side effects. They usually report less favorable results of treatment than indicated by audiometric tests.

New studies should be undertaken to compare different options of treatment of hearing loss in RA.

\section{Conclusion}

Hearing loss was present in $56.3 \%$ of the patients with rheumatoid arthritis, and it was predominantly sensorineural. Duration of disease and clinical activity of rheumatoid arthritis did not correlate to the incidence of hearing loss. Corticosteroid therapy, either peroral or intratympanic resulted in hearing improvement in about $60.0 \%$ of these patients. Results of methotrexate treatment of hearing loss in rheumatoid arthritis were unsatisfactory. Intratympanic steroids are safe for prolonged treatment of hearing loss in RA. Audiometric tests are recommended in order to control hearing in rheumatoid arthritis, and analyze the effect of proposed therapeutic procedures. 


\section{References}

1. Aletaha D, Neogi T, Silman AJ, Funovits J, Felson DT, Bingham CO III, Birnbaum NS, Burmester GR, Bykerk VP, Cohen MD, Combe B, Costenbader KH, Dougados M, Emery P, Ferraccioli G, Hazes JMW, Hobbs K, Huizinga TWJ, Kavanaugh A, Kay J, Kvien TK, Laing T, Mease P, Ménard HA, Moreland LW, Naden RL, Pincus T, Smolen JS, Stanislawska-Biernat E, Symmons D, Tak PP, Upchurch KS, Vencovský J, Wolfe F, Hawker G. 2010 Rheumatoid Arthritis Classification Criteria. Arthritis Rheum 2010; 62(9):2569-2581

2. Hajas A, Szodoray P, Barath S, Sipka S, Rezes S, Zeher M, Sziklai I, Szegedi G, Bodolay E. Sensorineural hearing loss in patients with mixed connective tissue disease: immunological markers and cytokine levels. J Rheumatol 2009; 36:1930-1936.

3. Garcia Callejo FJ, Conill Tobias N, Munoz Fernandez N, de paula Vernetta C, Alonso Castaneita I, Algarra JM. Hearing Impairment in patients with Rheumatoid Arthritis. Acta Otolaryngol Esp 2007; 58:232-238.

4. Takatsu M, Higaki M, Kinoshita H, Mizushima Y, Koizuka I. Ear involvement in patients with rheumatoid arthritis. Otol Neurotol 2005; 26:755-761.

5. Buniel MC, Geelan-Hansen K, Weber PC, Tuohy VK. Immunosuppressive therapy for autoimmune inner ear disease. Immunotherapy 2009; 1:425-434.

6. Matteson EL, Fabry DA, Facer GW, Beatty CW, Driscoll CL, Strome SE, McDonald TJ. Open trial of methotrexate as treatment for autoimmune hearing loss. Arthritis Rheum 2001; 45:146-150.

7. Harris JP, Weisman MH, Derebery JM, Espeland MA, Gantz BJ, Gulya AJ, Hammerschlag PE, Hannley M, Hughes GB, Moscicki R, Nelson RA, Niparko JK, Rauch SD, Telian SA, Brookhouser $\mathrm{PE}$. Treatment of corticosteroid-responsive autoimmune inner ear disease with methotrexate: A randomized controlled trial. JAMA 2003; 290:1875-1883.

8. Raut VV, Cullen J, Cathers G. Hearing loss in rheumatoid arthritis. J Otolaryngol 2001; 30:289-294.

9. Halligan CS, Bauch CD, Brey RH, Achenbach SJ, Bamlet WR, McDonald TJ, Matteson EL. Hearing loss in rheumatoid arthritis. Laryngoscope 2006; 116:2044-2049.

10. Oztürk A, Yalçin S, Kaygusuz I, Sahin S, Gök U, Karlidağ T, Ardiçoglŭ O. High-frequency hearing loss and middle ear involvement in rheumatoid arthritis. Am J Otolaryngol 2004; 25 : 411-417.

11. Bayazit YA, Yilmaz M, Gunduz B, Altinyay S, Kemaloglu YK, Onder M, Gurer MA. Distortion product otoacoustic emission findings in Behçet's disease and rheumatoid arthritis. ORL J Otorhinolaryngol Relat Spec 2007; 69:233-238.

12. Salvinelli F, D'Ascanio L, Casale M, Vadacca M, Rigon A, Afeltra A. Auditory pathway in rheumatoid arthritis. A comparative study and surgical perspectives. Acta Otolaryngol 2006; 126:32-36.

13. Dikici O, Muluk NB, Tosun AK, Unlüsoy I. Subjective audiological tests and transient evoked otoacoustic emissions in patients with rheumatoid arthritis: Analysis of the factors affecting hearing levels. Eur Arch Otorhinolaryngol 2009; 266:1719-1726.

14. Frade C, Martin C. Diagnostic value of the multifrequency tympanometry in active rheumatoid arthritis. Auris Nasus Larynx 1998; 25:131-136.

15. Milisavljevic D, Stankovic M, Zivic M, Radovanovic Z, Stankovic P. Changes of auditory ossicles in rheumatoid arthritis: scanning electron microscopic study. Eur Arch Otolaryngol 2010; 267: 363-366.
16. Salvinelli F, Cancilleri F, Casale M, Luccarelli V, Di Peco V, D'Ascanio L, De Martino A, Denaro V. Hearing thresholds in patients affected by rheumatoid arthritis. Clin Otolaryngol Allied Sci 2004; 29:75-79.

17. Dayal VS, Ellman M, Sweiss N. Autoimmune inner ear disease: Clinical and laboratory findings and treatment outcome. J Otolaryngol Head Neck Surg 2008; 37:591-596.

18. Quesnel S, Nguyen Y, Elmaleh M, Grayeli AB, Ferrary E, Sterkers O, Couloigner V. Effects of systemic administration of methylprednisolone on residual hearing in an animal model of cochlear implantation. Acta Otolaryngol 2011; 131:579-584.

19. Trune DR, Kempton JB, Harrison AR, Wobig JL. Glucocorticoid impact on cochlear function and systemic side effects in autoimmune C3.MRL-Faslpr and normal C3H/HeJ mice. Hear Res 2007; 226:209-217.

20. Sismanis A, Wise CM, Johnson GD. Methotrexate management of immune-mediated cochleovestibular disorders. Otolaryngol Head Neck Surg 1997; 116:146-152.

21. Inoue $\mathrm{Y}$, Tomemori T, Suzuki S, Arima T, Tomiita M, Shimojo N, Kohno Y. Low-dose oral methotrexate for the management of childhood Cogan's syndrome: A case report. Clin Rheumatol 2007; 26:2201-2203.

22. Lobo D, Trinidad A, García-Berrocal JR, Verdaguer JM, RamírezCamacho R. TNFalpha blockers do not improve the hearing recovery obtained with glucocorticoid therapy in an autoimmune experimental labyrinthitis. Eur Arch Otorhinolaryngol 2006; 263:622-626.

23. Matteson EL, Choi HK, Poe DS, Wise C, Lowe VJ, McDonald TJ, Rahman MU. Etanercept therapy for immune-mediated cochleovestibular disorders: A multi-center, open-label, pilot study. Arthritis Rheum 2005; 53:337-342.

24. Morovic Vergles J, Radic M, Kovacic J, Salamon L. Successful use of adalimumab for treating rheumatoid arthritis with autoimmune sensorineural hearing loss: Two birds with one stone. J Rheumatol 2010; 37:1080-1081.

25. Parnes LS, Sun AH, Freeman DJ. Corticosteroid pharmacokinetics in the inner ear fluids: An animal study followed by clinical application. Laryngoscope 1999; 109:1-17.

26. García-Berrocal JR, Ibáñez A, Rodríguez A, González-García JA, Verdaguer JM, Trinidad A, Ramírez-Camacho R. Alternatives to systemic steroid therapy for refractory immune-mediated inner ear disease: A physiopathologic approach. Eur Arch Otorhinolaryngol 2006; 263:977-982.

27. Oude Voshaar MA, Ten Klooster PM, Taal E, van de Laar MA Measurement properties of physical function scales validated for use in patients with rheumatoid arthritis: A systematic review of the literature. Health Qual Life Outcomes 2011; 9:99.

28. Garip Y, Eser F, Bodur H. Health-related quality of life in rheumatoid arthritis: Comparison of RAQoL with other scales in terms of disease activity, severity of pain, and functional status. Rheumatol Int 2011; 31:769-772.

29. Linde L, Sørensen J, Ostergaard M, Hørslev-Petersen K, Hetland ML. Health-related quality of life: validity, reliability, and responsiveness of SF-36, 15D, EQ-5D [corrected] RAQoL, and HAQ in patients with rheumatoid arthritis. J Rheumatol 2008; 35:1528-1537.

30. Dougados M, Ripert M, Hilliquin P, Fardellone P, Brocq O, Brault Y, Logeart I. The Influence of the definition of patient global assessment in assessment of disease activity according to the Disease Activity Score (DAS28) in rheumatoid arthritis. J Rheumatol 2011; 38:2326-2328. 